\title{
KINERJA PENILAIAN INDIVIDU MENGGUNAKAN ANALISIS KATEGORI YANG TEPAT DALAM PROSES PEMILIHAN KARYAWAN
}

\author{
Angga Widi ${ }^{1}$, Eko Wahyu ${ }^{2)}$., Ahedi Syukro ${ }^{3)}$ \\ Fakultas Ekonomi dan Bisnis, Universitas Narotama Surabaya \\ ${ }^{1)}$ E-Mail: febriwidi3@gmail.com \\ ${ }^{2)}$ E-Mail: kowahyunugroho@gmail.com \\ ${ }^{3)}$ E-Mail: \{ HYPERLINK "mailto:hedisyukro@gmail.com" \}
}

\begin{abstract}
For employers the process of employee selection is an important activity in the effort to get a workforce or adequate workers in receiving assignments to perform certain types of work. Many methods can be used in the employee selection process, one such method is category analysis. Whatever type of selection method, of course the company expects to achieve an accurate selection results. In writing this article the researcher wants to show one form of application of the method so that the selection result can give a picture of transparent result. This method is numerical using a score approach through a focus group discussion process. This categorical method is no less accurate than other similar methods in the recruitment selection process of employees in the company because it is quite objective.
\end{abstract}

\section{Keywords: performance appraisal, employee selection, categorical test}

Abstrak : Bagi pengusaha proses seleksi karyawan merupakan kegiatan penting dalam upaya mendapatkan tenaga kerja atau pekerja yang memadai dalam menerima penugasan untuk melakukan jenis pekerjaan tertentu. Banyak metode yang dapat digunakan dalam proses seleksi karyawan, salah satu metode tersebut adalah analisis kategori. Apapun jenis metode seleksi, tentu saja perusahaan mengharapkan untuk mencapai hasil seleksi yang akurat. Dalam menulis artikel ini peneliti ingin menunjukkan salah satu bentuk penerapan metode tersebut sehingga hasil seleksi dapat memberikan gambaran hasil yang transparan. Metode ini numerik menggunakan pendekatan skor melalui proses diskusi kelompok fokus. Metode kategoris ini tidak kurang akurat dibandingkan metode serupa lainnya dalam proses seleksi rekrutmen karyawan di perusahaan karena cukup obyektif.

\section{Kata kunci: penilaian kinerja, seleksi karyawan, analisa kategori}

\section{PENDAHULUAN}

Perusahaan, baik perusahaan besar maupun kecil, ikut berkontribusi terbesar dalam menggerakkan perusahaan adalah sumber daya manusia. Selain faktor sumber daya manusia, masih ada faktor lain yang menjadi pertimbangan modal, keterampilan dan pengetahuan. Tetapi faktor sumber daya manusia adalah faktor dominan dari perannya, dibandingkan dengan faktor lain. Dalam kegiatan ekonomi, perusahaan adalah bisnis yang berkesinambungan dan terarah. Untuk mencapai tujuan itu, banyak faktor yang harus dipertimbangkan untuk digunakan dalam kombinasi. Salah satu faktor utama adalah manusia yang memiliki kualitas yang dapat diandalkan. Di perusahaan, peran sumber daya manusia menjadi penentu keberhasilan suatu proses kerja, meskipun perannya dapat digantikan oleh robot, mesin, komputer atau peralatan lainnya. Karena peran sumber daya manusia sangat penting maka setiap perusahaan pasti akan membuat kebijakan untuk dapat 
mengatasi setiap masalah yang timbul terkait masalah yang dapat menghambat proses atau pencapaian tujuan (Nambudiri, 2010).

Satu masalah perusahaan yang perlu mendapat pemikiran khusus yaitu pemilihan karyawan yang akan ditugaskan untuk membawa pekerjaan. Umumnya fokus perusahaan adalah kualitas sumber daya manusianya dan metode seleksi. Perekrutan karyawan harus dilakukan secara akurat, dan dilakukan serta direncanakan dengan sebaik-baiknya agar sumber daya manusia yang didapat nantinya mampu menghasilkan manfaat yang optimal bagi perusahaan. Di sisi lain ketersediaan sumber daya manusia yang diinginkan oleh perusahaan terbatas, oleh karena itu penerapan metode seleksi merupakan faktor penting untuk kehidupan jangka panjang perusahaan.

\section{KAJIAN TEORI}

\section{Sumber Rekrutmen.}

Untuk memenuhi kebutuhan perusahaan akan tenaga kerja yang memadai dari keahliannya, perusahaan dapat menghitung dan memikirkan di mana sumber tenaga kerja dapat dipenuhi. Pertimbangan yang perlu dilakukan oleh perusahaan adalah:

1. Dalam kegiatan rekrutmen, memprioritaskan tenaga kerja perusahaan internal atau tenaga kerja dariluar?

2. Apa tingkat spesialisasi tenaga kerja yang dibutuhkan?

3. Apakah perlu untuk mempekerjakan kesetiaan kepada tenaga kerja untuk direkrut?

4. Apakah perusahaan menerapkan faktor senioritas dalam rekrutmen?

5. Apakah perlu mempertimbangkan pengembangan karyawan setelah proses rekrutmen selesai?

Selain pertimbangan di atas, perusahaan juga harus memikirkan dan membuat standar kompensasi tenaga kerja dan jumlah kebutuhan tenaga kerja serta tindakan nyata lebih lanjut untuk mendapatkan tenaga kerja.

Menurut Nitisemito (2015) untuk mendapatkan tenaga kerja yang tepat dapat dilakukan dengan cara sebagai berikut: "Jika perusahaan tidak bisa mendapatkan personil yang tepat, pekerjaan akan kurang, limbah bahan baku, pekerjaan akan lambat, banyak kerusakan dan hasil yang kurang memuaskan dan banyak lagi karena orang lain dapat terjadi dan sangat berbahaya bagi perusahaan. prihatin"

Berdasarkan pernyataan di atas, maka masalah rekrutmen tidak dapat diabaikan oleh perusahaan, lanjut menurut Winardi (2007), calon tenaga kerja yang akan dipilih berasal dari dua sumber, yaitu : "Sumber dari dalam perusahaan dan sumber luar perusahaan, selama sumbernya dapat memenuhi kebutuhan perusahaan dalam mencapai tujuannya"

\section{Sumber Rekrutmen : Internal.}

Tenaga kerja dalam perusahaan adalah sumber terbaik karena tenaga kerja di dalam perusahaan lebih terlatih, terutama mengenai pemahaman kondisi atau keadaan perusahaan. Tenaga kerja yang bersumber dari dalam perusahaan akan lebih berguna bagi perusahaan untuk memenuhi persyaratan jika perusahaan memiliki data lengkap tentang keahlian, pengalaman, evaluasi, penilaian tenaga kerja di lapangan, jadi jika ada lowongan atau lowongan kerja kosong di perusahaan ini dapat menjadi pertimbangan khusus bagi perusahaan untuk membuat keputusan serta pemilihan tenaga kerja yang dapat disertai dengan penugasan atau penempatan untuk mengisi lowongan tersebut.

Manfaat perekrutan pekerja dari dalam perusahaan mampu menciptakan kepuasan kerja, menghindari konflik, apresiasi terhadap kineria keria, mampu 
meningkatkan motivasi, meningkatkan loyalitas karyawan dan karyawan yang akrab dengan budaya kerja yang baik di perusahaan (Artaya, 2018).

\section{Sumber Rekrutmen : Eksternal.}

Sumber eksternal dapat dipertimbangkan jika ketersediaan tenaga kerja di perusahaan internal tidak mencukupi atau sangat terbatas untuk menempati area tertentu, sehingga alternatif perekrutan tenaga kerja dari eksternal menjadi pertimbangan yang wajar dan dinamis. Tujuannya adalah menyesuaikan spesifikasi pekerjaan.

Menurut Winardi (2007), sumber tenaga kerja yang berasal dari luar perusahaan dapat diperoleh melalui sumber-sumber berikut:

1. Tenaga kerja karyawan perusahaan,

2. Kelompok iklan,

3. Lembaga pendidikan atau pelatihan,

4. Agen tenaga kerja,

5. Daftar tunggu pelamar,

6. Pelamar yang datang langsung.

\section{Penilaian Program Perekrutan Karyawan.}

Tujuan dari penilaian ini adalah ukuran apakah program tersebut berhasil atau tidak. Keberhasilan program rekrutmen dapat diukur dengan kriteria berikut (Martoyo, 2015):

1. Jumlah pelamar,

2. Jumlah seleksi karyawan,

3. Jumlah penempatan karyawan yang sukses.

Meskipun ini bukan petunjuk biasa, program rekrutmen karyawan, ketentuan di atas tidak dapat menjamin keberhasilan program. Namun, jumlah penempatan karyawan yang sukses di bidangnya yang sesuai dengan kemampuan, keterampilan, pengetahuan, bakat, pendidikan, kesehatan, kondisi fisik, dan lain-lain. Dapat dianggap sebagai ukuran yang mampu mendeteksi pencapaian karyawan yang berhasil direkrut oleh perusahaan. Ini tentu akan memotivasi karyawan untuk bekerja lebih baik dan sungguh-sungguh.

\section{Pertimbangan Atribut Dalam Perekrutan.}

Setelah perusahaan dapat mengatur analisis posisi, dapat ditentukan atribut dan variabel apa yang harus dipenuhi oleh calon karyawan untuk dipilih dan diterima bekerja di perusahaan. Selanjutnya, perusahaan akan memanggil dan melakukan seleksi calon karyawan dari sumber tenaga kerja yang ada. Kandidat yang berhasil untuk pekerjaan harus tepat dan dapat beradaptasi dengan pekerjaan spesifik yang diberikan kepada karyawan.

Dalam melakukan seleksi (Artaya, 2018) ada beberapa atribut yang perlu diperhatikan, antara lain sebagai berikut:

1. Keahlian, untuk melaksanakan tugas, dibutuhkan keahlian sesuai dengan bidang, tujuannya adalah kelancaran dalam proses pelaksanaan pekerjaan.

2. Usia karyawan, kategori usia dalam pelaksanaan kerja di perusahaan dirasakan sangat penting bagi perusahaan, hal ini untuk menjaga kontinuitas dan produktivitas karyawan yang bersangkutan dalam jangka panjang sampai pada tingkat kemampuan karyawan.

3. Seks, untuk tugas tertentu, pemilihan karyawan berdasarkan jenis kelamin, mungkin karena faktor atau pertimbangan tertentu, beban kerja tertentu, presisi tertentu yang terwujud dalam pekerjaan itu sendiri. 
4. Kondisi fisik, kadang-kadang jenis pekerjaan tertentu membutuhkan kekuatan fisik yang sangat baik dan tidak perlu semua karyawan dapat diberikan tugas untuk melakukan jenis pekerjaan tertentu.

5. Pengalaman, menerima karyawan dengan pengalaman kerja spesifik, akan merasakan banyak manfaat, dan pekerjaan yang akan dibebankan langsung dapat dilakukan tanpa hambatan berarti.

6. Pendidikan, persyaratan pendidikan akan lebih berorientasi ke masa depan dalam hal pengembangan usaha, penempatan karyawan, promosi kerja atau pekerjaan yang berhubungan dengan karir.

7. Kesehatan, pada proses seleksi karyawan, faktor kesehatan tenaga kerja menjadi sesuatu yang penting karena dengan kesehatan karyawan akan dapat melakukan pekerjaan dengan baik dan terkait dengan produktivitas.

8. Kecerdasan emosional, ini membutuhkan perhatian khusus, terutama dalam kebutuhan untuk pengukuran dan penilaian ambisi, motivasi, disiplin, tanggung jawab, kesetiaan, dan pelamar keterampilan kerja yang akan ditugaskan untuk menjalankan pekerjaan nantinya.

9. Kepribadian, ukuran ini terlihat pada sikap dalam pelaksanaan tugas seharihari, berbentuk abstrak, sehingga membutuhkan alat ukur yang relatif.

10. Tingkat sosial, kondisi ini terkait dengan individu internal dan dapat memiliki efek tidak langsung pada individu dalam pelaksanaan tugas dan kegiatan kerja.

11. Kompensasi, atribut ini memiliki tendangan nyata terutama dalam meningkatkan kesejahteraan karyawan serta meningkatkan kondisi ekonomi yang terkait dengan semangat dan kepuasan kerja.

\section{Atribut Rekrutmen Standart.}

Untuk memastikan proses seleksi, penilaian dan pengukuran pelamar dapat dilakukan secara akurat, cepat dan terukur serta hasilnya dapat objektif maka perusahaan harus mampu menciptakan batas ukuran yang tepat agar dapat memenuhi harapan perusahaan. Jika bentuk penilaian dan pengukuran apa pun tidak dapat distandardisasi dengan benar, hal itu tidak dapat membahayakan perusahaan baik secara materi maupun moral, dan proses rekrutmen mungkin tidak berfungsi seperti yang diharapkan. Cukup dapat disajikan konsep rekrutmen seperti yang ditunjukkan di bawah ini:

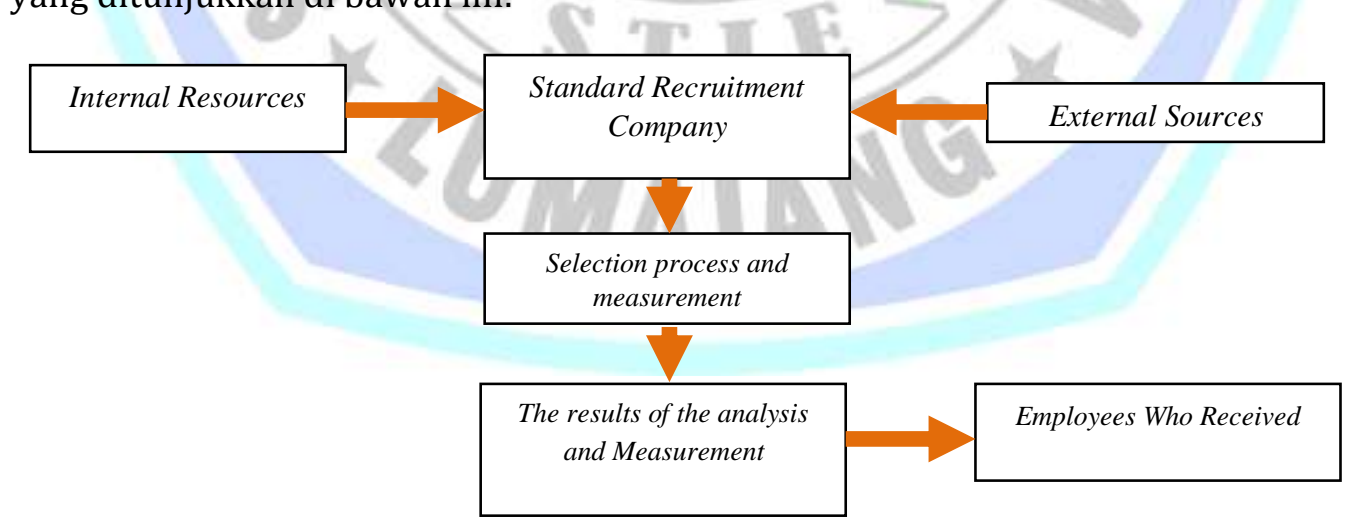

Gambar 1. Proses Perekrutan Dalam Suatu Perusahaan. Sumber: Winardi, 2007, Manajemen Perilaku Organisasi, Prenada Media, Jakarta. 


\section{METODE}

\section{Lokasi Objek Penelitian.}

Merupakan salah satu pabrik gula yang terletak di pura, tepatnya di jalan raya candi nomor 10 Sidoarjo, pabrik gula yang cukup tua, berdiri sejak tahun 1896 ketika masih di bawah pemerintahan kolonial Belanda. Dan sekarang statusnya menjadi PTP (Plantation Limited Liability Company) dan masuk ke area PTP XII-XIII. Operasional di bawah koordinasi PT. Rajawali Nusantara (Persero) dan berkantor di Jalan Undaan Kulon Nomor 57-59 Surabaya.

\section{Model Pengukuran Data.}

Proses rekrutmen karyawan maka model pengukuran data menggunakan data numerik dengan pendekatan data kategori, dengan pengaturan sebagai berikut (Santoso, 2012):

1 = Sangat tidak memuaskan

2 = Tidak memuaskan

$3=$ Kurang memuaskan

$4=$ Memenuhi

5 = Sangat memuaskan

\section{HASIL DAN PEMBAHASAN}

\section{Model Analisis Data.}

Pada dasarnya penerapan tes Kategorikal yang sebenarnya untuk menguji atau mendiagnosa gejala dalam pengukuran menggunakan skala numerik. Analisis kategori menggunakan data non-metrik dan dalam banyak kasus data yang digunakan adalah data nominal (kategori). Proses uji yang sedikit berbeda yaitu menggunakan sintaks adalah serangkaian perintah yang digunakan untuk menjalankan metode tertentu. Dengan menggunakan sintaks maka data yang dianalisis dapat dieksekusi langsung (run). Output Syntax adalah grafik berbentuk peta (Santoso, 2012).

\section{Contoh Penelitian.}

Dalam kasus penelitian ini, subyek penelitian adalah 7 (tujuh) pelamar, yang akan berlaku sebagai manajer di pabrik gula. Setiap pelamar akan diuji menggunakan 11 (sebelas) pemilihan atribut yang telah ditetapkan perusahaan di atas.

\section{DISKUSI}

Implementasi Analisis Kategori. Pada awal kategori analisis akan menampilkan hasil penilaian 7 (tujuh) pelamar melalui proses diskusi kelompok dari tim penilai. Tampilan data adalah sebagai berikut:

Tabel 1. Hasil Tim Diskusi Kelompok Diskusi Internal Perusahaan.

\begin{tabular}{|c|r|c|c|c|c|c|c|c|}
\hline No. & Atribute & P1 & P2 & P3 & P4 & P5 & P6 & P7 \\
\hline 1. & Expertise & 3 & 4 & 2 & 4 & 4 & 5 & 3 \\
\hline 2. & The age of & 4 & 4 & 5 & 4 & 4 & 5 & 5 \\
\hline 3. & Gender & 5 & 5 & 5 & 5 & 5 & 5 & 5 \\
\hline 4. & Physical Condition & 3 & 4 & 4 & 5 & 5 & 4 & 5 \\
\hline 5. & Experience & 3 & 5 & 5 & 4 & 3 & 3 & 5 \\
\hline 6. & Education & 5 & 5 & 5 & 5 & 5 & 5 & 5 \\
\hline
\end{tabular}




\begin{tabular}{|c|r|c|c|c|c|c|c|c|}
\hline 7. & Health & 4 & 5 & 5 & 3 & 4 & 5 & 4 \\
\hline 8. & $\begin{array}{r}\text { Emotional } \\
\text { Intelligence }\end{array}$ & 5 & 4 & 4 & 5 & 5 & 4 & 4 \\
\hline 9. & Personality & 4 & 4 & 4 & 5 & 5 & 4 & 4 \\
\hline 10. & The Level Of Social & 4 & 3 & 2 & 5 & 3 & 3 & 5 \\
\hline 11. & Compensation & 3 & 3 & 5 & 4 & 4 & 3 & 5 \\
\hline
\end{tabular}

Sumber: Hasil Tim Penilai Perusahaan Grup Penilai.

$\mathrm{P}=$ Pelamar.

Hasil penilaian tim dari kelompok di atas, selanjutnya akan menjadi masukan dalam kategori analisis melalui sintaks eksekusi, sehingga melalui proses sintaks akan diambil hasilnya dalam bentuk grafik sebagai berikut:
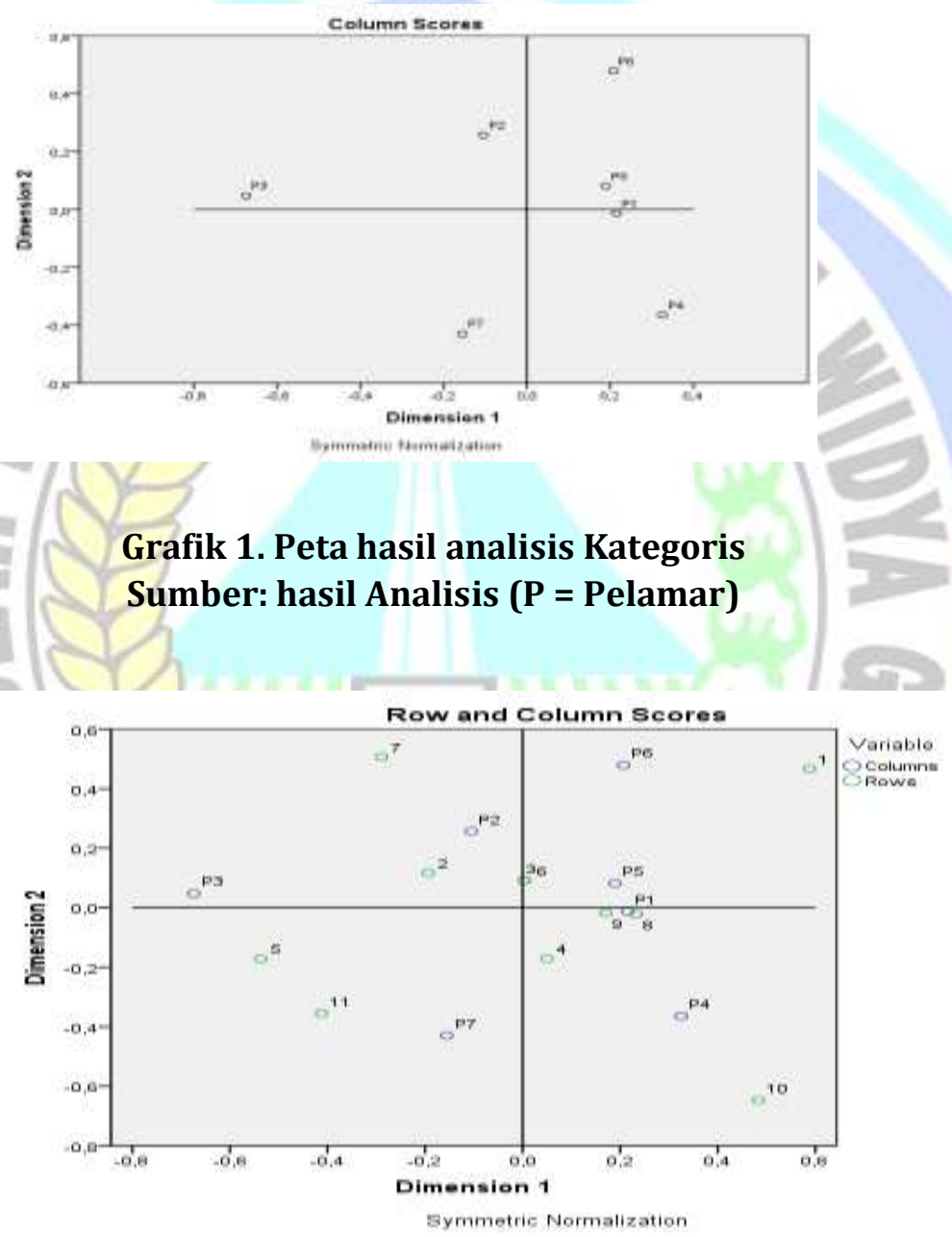

Grafik 2. Peta hasil analisis Kategoris Sumber: hasil Analisis ( $\mathrm{P}=$ Pelamar)

Untuk membahas hasil kategori analisis, grafik yang hanya menampilkan bagan nomor tiga, karena grafik ketiga adalah tampilan grafik yang paling lengkap, berisi atribut dan posisi dari tujuh pelamar dalam satu tampilan.

Grafik dibagi dalam dua dimensi, yaitu dimensi 1 dan 2 dimensi. Dimensi 1 semakin ke nilai yang tepat semakin besar dan titik sumbu nositif dihitung dari 
Tengah, bergerak ke kanan secara horizontal. Apakah dimensi 2, dihitung dari tengah sumbu, titik ke atas nilai semakin besar dan positif. Bergerak secara vertikal. Pelamar yang berada di area yang positif (dimensi 1 dan dimensi2) memenuhi syarat untuk dipertimbangkan untuk diterima dalam kondisi berikut:

1. Para pelamar yang paling layak adalah pelamar yang diterima 6 (P6) karena posisinya berada di kuadran 1, yaitu persimpangan (arsiran) antara dimensi 1 dan 2 dimensi. Jika perusahaan hanya membutuhkan satu karyawan saja pelamar 6 (P6) yang layak.

2. Sebuah alternatif yang layak dipertimbangkan pelamar lain untuk pelamar yang diterima adalah 4 (P4) dan pelamar 2 (P2), karena nilainya positif dalam setiap dimensi dan posisi yang paling dekat dengan pelamar 6 (P6). Jika perusahaan membutuhkan tiga karyawan, maka pelamar yang diterima bernilai 6, 4, pelamar dan pelamar 2 .

3. Jika perusahaan membutuhkan 6 (enam) karyawan untuk diterima maka layak untuk diterima adalah 4, pelamar pelamar pemohon 6, 2, 1, pelamar pelamar pemohon 3, dan 5. Karena keenam pelamar berada di daerah yang nilai positif (dimensi 1 atau dimensi 2)

4. Hanya satu orang pelamar yang tidak memenuhi syarat untuk diterima bekerja di perusahaan yaitu pelamar 7, karena pelamar 7 area (kuadran) yang negatif (baik dimensi 1 dan dimensi 2).

Berdasarkan pembahasan di atas, terlihat dengan jelas bahwa kebijakan perusahaan untuk menerima karyawan ditentukan oleh posisi pelamar pada grafik di atas, dan keputusan yang dilakukan oleh perusahaan secara fleksibel, yang tergantung pada seberapa besar kebutuhan tenaga kerja atau karyawan yang akan di rekrut melalui proses di atas.

\section{PENUTUP}

\section{Simpulan}

Kesimpulan. Jika metode rekrutmen perusahaan dilakukan secara obyektif dan murni metode analisis numerik, maka kategori dapat dijadikan alternatif atau pilihan, karena penggunaan atribut dalam proses rekrutmen sangat logis dan mendekati nilai obyektifnya. Artinya hasil yang disajikan dalam grafik dapat secara signifikan dipertanggujawabkan kebenaran. Sehingga mampu memberikan data dan informasi yang akurat kepada perusahaan dalam hal karyawan dan rekrutmen dapat menjadi pertimbangan bagi HRD di perusahaan pihak internal.

Saran. Metode ini dapat diterapkan secara obyektif dengan kegiatan rekrutmen yang lebih luas untuk keperluan karyawan atau karyawan, jika perlu jumlah atribut yang digunakan dapat direproduksi dalam jumlah sehingga proses rekrutmen dapat didasarkan pada nilai yang paling obyektifitas mendekati kebenaran, sehingga dapat mengukur seluruh nilai yang mewakili seorang karyawan juga. Dan pada akhirnya nilai yang dihasilkan melalui metode perhitungan numerik pendekatan keputusan ini mencakup seluruh sintaks yang berlaku cukup pada individu ketika karyawan bekerja secara obyektif pada perusahaan. 


\section{DAFTAR RUJUKAN}

Artaya, I Putu., 2018, Dasar-Dasar Manajemen Operasi dan Produksi, Narotama University Press, Surabaya.

Artaya, I Putu., 2018, Pengaruh Sikap Dan Keyakinan Konsumen Dalam Keputusan Pembelian Tepung Terigu Merek Gunung Bromo Produk PT. Bogasari Flour Mils Surabaya, Bisma (Bisnis dan Manajemen), Unesa, 1 (1).

Artaya, I Putu., Kamisutara, M., Baktiono, RA., 2018, Pengaruh Citra Produk Berdasarkan Analisis Persepsi Konsumen Pada Kelompok Usaha Aneka Pangan Di Sidoarjo, E-Jurnal Tata Sejuta STIA Mataram, Vol. 4, No. 1.

Hasibuan, Malayu S.P., 2014, Organisasi dan Motivasi: Dasar Peningkatan Produktivitas, Bumi Aksara, Jakarta

Martoyo, Susilo, 2010, Manajemen Sumber Daya Manusia, BPFE, Yogyakarta

Nambudiri, W., Cascio. R., 2010, Managing Human Resources: Productivity, Quality of Work Life, Profits, McGraw Hill, Higher Education, New Jersey.

Nitisemito, Alex, 2015, Manajemen Personalia, Ghalia Indonesia, Jakarta

Pribadiyono, 2002, Mengembangkan Kompetensi Individu Dan Daya Saing Organisasi Di Indonesia, Konferensi I APIO, Surabaya.

Rivai, Veithzal, 2014, Manajemen Sumber Daya Manusia Untuk Perusahaan: Dari Teori Ke Praktisi, Rajawali Press, Jakarta

Santoso, Singgih, 2012, Mengukur Sikap dan Kepuasan Konsumen, Penerbit: PT. Elex Media Komputindo, Jakarta

Umar, Husein, 2002, Evaluasi Kinerja Perusahaan, Gramedia Pustaka Utama, Jakarta

Winardi, 2007, Manajemen Perilaku Organisasi, Prenada Media, Jakarta. 